UDK 551.583:316.42

https://doi.org/10.18485/fb_ic4hs.2018.16

\title{
INCREASE IN CLIMATE CHANGE AND ITS IMPACT ON THE VULNERABILITY OF SOCIAL COMMUNITIES
}

\author{
Miloš TOMIĆ* , Sandra TOŠIĆ ${ }^{* *}$
}

\begin{abstract}
Climate change is one of the most important ecological threats of the twentyfirst century, and it has significant implications for the quality of life of millions of people across the globe. Findings of numerous empirical studies show that the effects of climate change, such as temperature increase, melting of ice, rising sea and ocean levels and changes in rainfall rates, have a significant impact on the functioning of human society. At the beginning of new millennium, climate change has significantly contributed to the emergence of extreme natural disasters. Namely, the increasingly frequent occurrence of floods, droughts, earthquakes, storms, volcanic eruptions, hurricanes, and tsunamis is directly proportional to the increase in the vulnerability of human communities. Climate change will also continually endanger agricultural production and the safety of food supplies. Production and availability of food and water, human health, transport, energy supply are just some of the elements on which the functioning of human communities is based, and which are highly dependent on climatic conditions and which can be significantly destabilized by climate change. This state of affairs is confirmed by a large number of scientific studies that indicate that the use of obsolete technologies and common rules of behaviour dramatically accelerate temperature disproportions that negatively affect the basic conditions of human life (access to drinking water, food, use of the natural environment). Anthropogenic activities, in addition to natural ones, are considered to be the main cause of greenhouse gas emissions, resulting in a global increase in average air temperature. By developing and applying modern technology, gases contributing to the greenhouse effect would be greatly reduced. The rise of average temperature induces sudden meteorological changes at all levels (global, regional and national). The uneven distribution of the impact of climate change caused the need for an effective preventive response, especially due to the fact that the poorest countries are extremely vulnerable. An effective response to climate change and its inevitable consequences depend on several factors: the seriousness of the situation (familiarizing the public with the problem of climate change), programme policy (strategic documents) and the development of institutional capacity. Solving the climate change problem will
\end{abstract}

\footnotetext{
* PhD Student University of Belgrade Faculty of Security Studies, milosttomic@yahoo.com

** PhD Student, University of Belgrade Faculty of Security Studies, sandratosic93@hotmail.com
} 
inevitably determine the future economic and, therefore, social development of many countries in different parts of the world.

Keywords: climate change, vulnerability of social community, lack of resources, natural disasters, modern technologies.

\section{INTRODUCTION}

The increasingly frequent occurrence of extreme natural disasters and other climatic phenomena with devastating consequences that necessarily accompany them has led to the need for an effective strategic response to the ever-growing climate change. Climate risk management, especially in those underdeveloped ${ }^{1}$ and less developed parts of the world, reduces the vulnerability of social communities while providing necessary prerequisites for stable social and economic development.

The increased concentrations of greenhouse gases (GHG) (carbon dioxide, methane, and water vapour, amongst others) in the atmosphere are accelerating the occurrence of a natural phenomenon known as the greenhouse effect. The proliferation of GHG in the atmosphere is elevating the mean temperature of the world, both of land and sea, at a much faster rate than ever seen before on the planet (Intergovernmental Panel on Climate Change (IPCC), 2012; World Meteorological Organization (WMO), 2013). Accordingly, Arndt and associates state that this can cause serious climate modifications (see Figure 1) with certain growth indicators (Arndt, et al., 2010) whereby security threats occur as the direct consequences that threaten the social, political, environmental and economic values of a country.

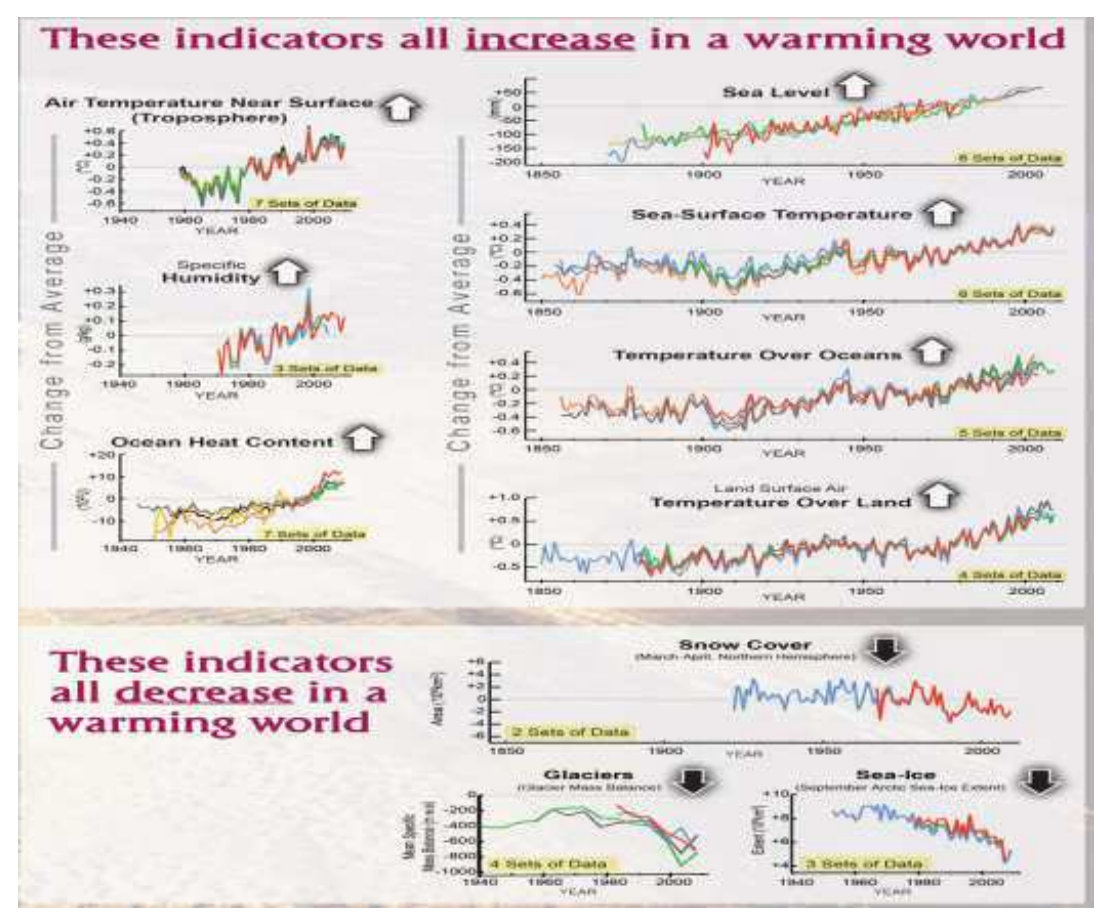

Figure 1. Indicators of climate change

Source: Arndt, et. al., 2010

${ }^{1}$ Poverty is an important aspect of vulnerability because of its direct association with access to resources which affects both baseline vulnerability and coping from the impacts of extreme events (Adger, 1999). 
Therefore, it is necessary to seriously address the problem of climate change, especially due to the fact that it represents a catalyst for the development of unwanted climatic and other events. Although studies suggest that these changes will not be negative for all countries and territories, they do indicate that these transformations will inevitably alter current livelihoods (IPCC, 2012).

\section{DEFINING VULNERABILITY}

In scientific literature, the notion of vulnerability is often unevenly defined. Kelly and Adger (2000) state that 'the concept of vulnerability is broadly defined and categorized depending on the level (functionality) and scope of the analysis.' The very concept of vulnerability has developed over time through various scientific disciplines (political ecology, human ecology, physical science, and spatial analysis), modelling a number of definitions conditioned primarily by concrete methodological and epistemological approaches (Cutter 1996; Thywissen, 2006; Deressa et al., 2008).

Two major vulnerability research traditions have arguably been the source of ideas for research into integrated human-environment vulnerability, namely, analysis of vulnerability as 1. 'lack of entitlements in livelihoods', traditionally used to explain food insecurity, and 2. social impacts of 'natural hazards', developed to explain the commonalities between different types of natural catastrophes and their societal impacts (Adger 2006).

Intergovernmental Panel on Climate Change (IPCC) in its Fourth Assessment Report defines vulnerability as: 'the degree to which a system is susceptible to, or unable to cope with, adverse effects of climate change, including climate variability and extremes. Vulnerability is a function of the character, magnitude, and rate of climate variation to which a system is exposed, its sensitivity, and its adaptive capacity' (IPCC, 2007: 93).

Therefore, the basic constituent elements of the definition proposed by the IPCC are exposure, sensitivity, and adaptive capacity ${ }^{2}$. These three elements are considered the main components of the concept of vulnerability in extreme natural disasters (floods, droughts, volcanic eruptions, storms, hurricanes, tsunamis and earthquakes) caused by climate change.

\section{CONSIDERATION OF THE CONCEPT OF SOCIAL VULNERABILITY TO CLIMATE CHANGE}

Essential feature of a model of social vulnerability ${ }^{3}$ to climate change is, first of all, that it focuses on social aspects of the phenomenon (Adger, 1999). The principal finding of the

${ }^{2}$ Exposure component is related to the nature and degree to which a system is exposed to a series of changes, particularly in the valued constituents ??. Sensitivity can be viewed as the degree to which a system is affected by climate variability or change. Adaptive capacity is related to the potential of a system to develop and integrate certain measures in order to effectively deal with the expected impacts (Parry et. al., 2007).

${ }^{3}$ In many cases social vulnerability is most often described using the individual characteristics of people (age, race, health, income, type of dwelling unit, employment) (Shirley et al., 2012). 
social vulnerability studies is that it is the social processes that 'generate unequal exposure to risk by making some people more prone to disaster than others, and these inequalities are largely a function of the power relations operative in every society' (Hilhorst and Bankoff, 2007:2).

Climate change presents an uncertain but potentially serious threat to vulnerable populations (Bohle et al., 1994). Climate events can result in irreversible losses of human and physical capital and may cause poverty traps (Heltberg et al., 2009). Developing countries are particularly vulnerable to climate change impacts because of exposure and sensitivity to climate change and because some elements of the capacity to adapt may be limited: hence biophysical and social vulnerability (McCarthy et al, 2001). Furthermore, climate change is directly affecting the living conditions of most of the people in developing countries, through increasing variability and uncertainty of the conditions in which people try to pursue their livelihoods (IPCC 2007).

A longitudinal study in Zimbabwe followed children that were less than 2 years old (the at which children are most susceptible to malnutrition) when a severe drought hit in the early 1980s (Heltberg et al., 2009). Those that survived the famine were found to be stunted, translating into lower schooling achievements, inferior adult health, and an estimated 14\% reduction in lifetime earnings (Alderman et al., 2006).

The last decade of the twentieth century was marked by the appearance of extreme natural phenomena. Kelly and Adger (Kelly \& Adger, 2000:332-333) describe in their work the devastating effects of the Linda Storm that hit South Vietnam in 1997. Namely, the authors state that the material damage amounted to US\$ 600 million, with 778 people being killed while 2132 persons were missing.

Agriculture is inherently sensitive to climate conditions and is among the most vulnerable sectors to the risks and impacts of global climate change (Parry and Carter 1989; Reilly 1995; Desanker \& Magadza, 2001; Smit, \& Skinner, 2002). In many countries around the world, food production plays a central role in modelling and implementing a national policy for maintaining general well-being and health of people. Piao and colleagues (Piao et al., 2010) cite the example of China as a country in which the effects of climate change dramatically jeopardize (directly or indirectly) the safety of food production and the survival of over 1.3 billion people. In addition, the authors emphasize that each state must individually take the necessary measures for strengthening adaptive capacities through appropriate program policies (adoption of 'ecological' laws, application of modern technology with low emission of pollutants, sustainable use of drinking water) and efficient institutional response at all levels of government), because understanding of the present climate variability in society will reduce the impacts of climate change (Adger, 1998) on individuals and society.

\section{MITIGATION OF AND ADAPTATION TO CLIMATE CHANGE}

Social communities that are facing reduced quality of life due to climate change have at their disposal two basic response strategies: mitigation of climate change and adaptation to climate change (Dimitrijevic, 2010). Mitigation refers to limiting the consequences of global climate change through reducing greenhouse gas emissions and increasing carbon dioxide absorption capacity (IPCC, 2014). Adaptation is primarily aimed at alleviating 
harmful effects of inevitable climate change through a wide range of actions which target an endangered system (Füssel, \& Klein, 2006; Locatelli, 2011). The objective of mitigating climate change is to adopt measures to limit the volume of climate change.

Adaptation and mitigation, as two basic responses to climate change, differ from one another, especially with regard to the objectives of implementation. Mitigation is directed at causes, while the adaptation is focused on the impact of climate change. The results of various research studies show that confronting climate change involves the use of both approaches (Fussel, 2007; Schipper, 2006; Ringius et al., 2002; Muller, 2001). Even with a reduction in greenhouse gas emissions, an increase in global temperatures and other climate change is expected (Zhang, et al., 2011). On the other hand, the adaptation will not be able to eliminate all the negative effects. Accordingly, adaptation and mitigation are key to limiting changes in the climate system. In addition to the goal, the difference between mitigation and adaptation is related to spatial impact. Mitigation has a global, while the adaptation has, at best, regional, but mostly local domain (Klein, et al., 2005).

Mitigation refers to reducing the vulnerability of the community using different technical solutions. Among the potential solutions proposed for mitigation of climate change, the greatest attention in the scientific literature and public debates is paid to two different approaches, related to the concentration of carbon dioxide and other gases that contribute to the greenhouse effect in the Earth's atmosphere. Stabilization of carbon dioxide concentration in the atmosphere can be achieved by reducing emissions (carbon sources) or by the natural adoption of atmospheric carbon dioxide by the ocean and terrestrial ecosystems. The second technique consists of the artificial absorption of carbon dioxide from the atmosphere (based on physical and chemical processes) followed by its injection. Mitigating the effects of climate change involves the implementation of different approaches, such as solar radiation management, abatement of emissions, carbon trapping in biomass carbon capture, and geological storage (Zhang, et al., 2011)

Adaptation is the process of adapting ecological, social or economic systems in response to actual or expected climate stimulation and their effects or impacts (IPCC, 2014: 1758). Adaptation is a socio-institutional process that involves cycles of anticipation and response to a variety of stressors (Tschakert \& Dietrich 2010). Effective adaptation to climate change depends on the availability of two important prerequisites: information on what to adapt and how to adapt (Adger, et al., 2005). Adaptation involves a wide range of measures, including technical, institutional, legal, educational and other measures. Research and data collection can also be considered adaptive measures (in the broad sense) because they facilitate the implementation of climate risk mitigation measures (Fussel, 2007: 266).

Adapting to climate change and risks takes place in a dynamic social, economic, technological, biophysical and political context that differs in time, location and sector. These complex conditions determine the capacity of the adjustment system (Smit \& Pilifosova, 2003). Adaptive capacity is the potential or ability of a system, region or community to adapt to the effects or impacts of climate change (IPCC, 2014: 169). Improving adaptive capacity is a practical means of overcoming changes and uncertainties in the climate, including variability and extremes. The main characteristics of communities 
or regions that seem to determine their adaptive capacity are: economic wealth, technology, information, infrastructure and institutions (Smit \& Pilifosova, 2003).

The application of different adaptation technologies can reduce the current and future vulnerability to climate change. Adaptation technology can be defined as 'the application of technology to reduce vulnerability or increase the resilience of natural or human systems to the impacts of climate change' (UNFCCC, 2005: 5). These technologies can be classified as 'heavy' technologies, such as equipment and infrastructure, and 'soft' technologies, including management practices and institutional arrangements (Christiansen et al., 2011). This division is conditional because some technologies, such as new varieties of crops, are not easy to classify.

\section{CONCLUSION}

The last two decades have been characterized by a significant increase in academic interest in investigating the impact of climate change on all types of natural and social systems. The direct effects of climate change are the rise in temperature, ice melting, rise in sea and ocean level, and changes in precipitation patterns. These consequences are causing significant problems in the functioning of social communities. The change in weather conditions threatens food production; the rise in sea level will have an impact on the coastal environment and infrastructure, extreme weather conditions will become more and more serious and can cause destruction (IPCC, 2014). The increase in the frequency of catastrophic events such as floods, droughts, fires is also a consequence of climate change. It is very likely that mankind will be exposed to an increased risk of such occurrences. At the beginning of the 21 st century, the issue of climate change has come into focus of the international community's interest. The international scientific community has concluded that there are two main approaches to dealing with climate change and reducing the vulnerability of social communities: mitigation and adaptation. The inability to overcome the effects of climate change through the application of adequate technologies makes developing countries more vulnerable to instabilities and conflicts.

\section{REFERENCE}

Adger, W. N. (1998). Indicators of social and economic vulnerability to climate change in Vietnam. London: University College London.

Adger, W. N. (1999). Social vulnerability to climate change and extremes in coastal Vietnam. World development, 27(2), 249-269.

Adger, W. N., Arnell, N. W., \& Tompkins, E. L. (2005). Successful adaptation to climate change across scales. Global environmental change, 15(2), 77-86.

Arndt, D. S., et. al. (Eds.). (2010). State of the Climate in 2009. Bulletin of the American Meteorological Society. 91 (7), 79-106.

Alderman, H., Hoddinott, J., Kinsey, B., 2006. Long term consequences of early childhood malnutrition. Oxford Economic Papers 58 (3), 450-474. 
Bohle, H. G., Downing, T. E., \& Watts, M. J. (1994). Climate change and social vulnerability: toward a sociology and geography of food insecurity. Global environmental change, 4(1), 37-48.

Christiansen, L., Olhoff, A., \& Trærup, S. (2011). Technologies for adaptation: perspectives and practical experiences. UNEP Risø Centre, Roskilde.

Desanker, P. and Christopher M. (2001). Africa. In McCarthy, JJ et al. Climate Change 2001: Impacts, Adaptation and Vulnerability (Contribution of Working Group II to the Third Assessment Report of the Intergovernmental Panel on Climate Change). Cambridge: Cambridge University Press.

Dimitrijević, D., (2010) Trendovi ekološke bezbednosti u XXI veku, Univerzitet u Beogradu, Fakultet bezbednosti, Beograd

Füssel, H. M., \& Klein, R. J. (2006). Climate change vulnerability assessments: an evolution of conceptual thinking. Climatic change, 75(3), 301-329.

Fussel, H.M. (2007). Adaptation planning for climate change: concepts, assessment approaches, and key lessons. Sustainability Science, 2(2), 265-275.

Klein, R. J., Schipper, E. L. F., \& Dessai, S. (2005). Integrating mitigation and adaptation into climate and development policy: three research questions. Environmental science \& policy, 8(6), 579-588

Kelly, P. M., \& Adger, W. N. (2000). Theory and practice in assessing vulnerability to climate change and Facilitating adaptation. Climatic change, 47(4), 325-352.

IPCC (2007). Climate Change 2007 : Impacts, Adaptation and Vulnerability. Contribution of Working Group II to the Fourth Assesment Report of the Intergovernmental Panel on Climate Change. Cambridge: Cambridge University Press.

IPCC. (2012). Managing the risks of extreme events and disasters to advance climate change adaptation. Cambridge: Cambridge University Press..

IPCC, (2014). Climate Change 2014: Impacts, Adaptation, and Vulnerability. Part A: Global and Sectoral Aspects. Contribution of Working Group II to the Fifth Assessment Report of the Intergovernmental Panel on Climate Change, Cambridge University Press, Cambridge, United Kingdom and New York.

Locatelli, B. (2011). Synergies between adaptation and mitigation in a nutshell. CIFOR.

Muller, B. (2001). Varieties of distributive justice in climate change: an editorial comment. Climatic Change, 48(2-3), 273-288.

McCarthy, JJ; Canziani, OF; Leary NA; Dokken DJ; and KS White. 2001 Climate Change 2001: Impacts, Adaptation and Vulnerability (Contribution of Working Group II to the Third Assessment Report of the Intergovernmental Panel on Climate Change). Cambridge: Cambridge University Press.

Parry, M. L., et. al. (Eds.). (2007). Climate Change 2007: Impacts, Adaptation and Vulnerability. Contribution of Working Group II to the Fourth Assessment Report of the Intergovernmental Panel on Climate Change. Cambridge and New York: Cambridge University Press..

Parry, M.L. and Carter, T.R. (1989). 'An assessment of the effects of climatic change on agriculture', Climate Change 15, 95-116. 
Protocol, K. (1997). United Nations framework convention on climate change. Kyoto Protocol, Kyoto, 19.

Piao, S., Ciais, P., Huang, Y., Shen, Z., Peng, S., Li, J., ... \& Friedlingstein, P. (2010). The impacts of climate change on water resources and agriculture in China. Nature, 467(7311), 43.

Ringius, L., Torvanger, A., \& Underdal, A. (2002). Burden sharing and fairness principles in international climate policy. International Environmental Agreements: Politics, Law and Economics, 2(1), 1-22.

Reilly, J. (1995). 'Climate change and global agriculture: Recent findings and issues', American Journal of Agricultural Economics 77, 727-733.

Tschakert, P., and Dietrich, K.A. (2010). Anticipatory Learning for Climate Change Adaptation and Resilience. Ecology and Society, 15(2): 11

Thywissen, K. (2006). Core terminology of disaster reduction: A comparative glossary. In .Birkmann, J. (ed.) Measuring vulnerability to natural hazards: Toward disaster resilient societies. Press. Hong Kong: United Nations University.

Smit, B., \& Pilifosova, O. (2003). Adaptation to climate change in the context of sustainable development and equity. Sustainable Development, 8(9), 9.

Schipper, E.L.F. (2006). Conceptual history of adaptation in the UNFCCC process. Review of European Community and International Environmental Law (RECIEL), 15(1), 82-92.

Shirley, W. L., Boruff, B. J., \& Cutter, S. L. (2012). Social vulnerability to environmental hazards. In Hazards Vulnerability and Environmental Justice (pp. 143-160). New York: Routledge.

Smit, B., \& Skinner, M. W. (2002). Adaptation options in agriculture to climate change: a typology. Mitigation and adaptation strategies for global change, 7(1), 85-114.

Kely, P. M. and Adger, W. N. (2000). Theory and practice in assessing vulnerability to climate change and facilitating adaptation. Climatic Change. 47 (4), 325-352.

Hilhorst, D. \& Bankoff, G. (2007). Introduction : Mapping Vulnerability In: Bankoff, G., Frerks, G. \& Hilhorst, D. (eds.) Mapping Vulnerability : Disasters, Development and People. London: Earthscan.

Heltberg, R., Siegel, P. B., \& Jorgensen, S. L. (2009). Addressing human vulnerability to climate change: toward a 'no-regrets' approach. Global Environmental Change, 19(1), 89-99.

Zhang, T. C., Ojha, C. S. P., Tyagi, R., \& Kao, C. (2013, February).Climate Change Modeling, Mitigation, and Adaptation. American Society of Civil Engineers.

WMO. (2013). WMO statement on the status of the global climate in 2012. Geneva: World Meteorological Organization. 